\title{
Association of midazolam with ketamine in giant Amazon river turtles Podocnemis expansa breed in captivity ${ }^{1}$
}

\author{
Associação de midazolam com cetamina em tartarugas da Amazônia Podocnemis expansa de \\ cativeiro
}

\author{
José Roberto Ferreira Alves-Júnior', Andréa Cristina Scarpa Bosso"I, Mariana Batista Andrade ${ }^{\mathrm{II}}$, Karin Werther"II, André Luiz \\ Quagliatto Santos ${ }^{\mathrm{IV}}$
}

\begin{abstract}
${ }^{\mathrm{I}}$ Master, Veterinarian, Veterinary Sciences, UFU, Uberlandia-MG, Brazil. Conception, design, data acquisition, interpretation of the data, drafting and revising of the article, responsible for anaesthesia procedure and for the integrity of the research as a whole.

IIMaster, Veterinarian, Veterinary Sciences, UFU, Uberlandia-MG, Brazil. Data acquisition, critical revision, responsible for anaesthesia procedure.

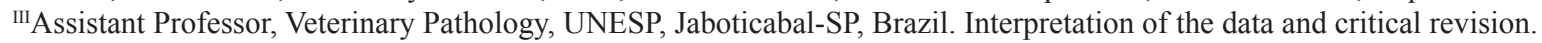

${ }^{\text {IV }} \mathrm{PhD}$, Full Professor, Animal Anatomy, Wild Animals Research Laboratory, UFU, Uberlandia-MG, Brazil. Conception, design, data acquisition and interpretation of the data, critical revision, responsible for anaesthesia procedure.
\end{abstract}

\begin{abstract}
PURPOSE: Evaluate the effects of two anesthetic associations in giant Amazon river turtles (P. expansa).

METHODS: Twenty P. expansa, healthy, of both sexes, with weights between 1.0 and $1.5 \mathrm{~kg}$ of a commercial breeding facility located in the valley of the Araguaia River, Goiás, Brazil, were divided into two groups ( $G 1 \mathrm{n}=10$ and $\mathrm{G} 2 \mathrm{n}=10$ ). Each group received a protocol being: $\mathrm{P} 1=$ midazolam $(2 \mathrm{mg} / \mathrm{kg} \mathrm{IM})$ and ketamine $(20 \mathrm{mg} / \mathrm{kg} \mathrm{IM})$ and $\mathrm{P} 2=$ midazolam $(2 \mathrm{mg} / \mathrm{kg} \mathrm{IM})$ and ketamine $(60$ $\mathrm{mg} / \mathrm{kg} \mathrm{IM}$ ), applied on G1 and G2, respectively. The drugs were applied in the left forelimb. The clinical parameters evaluated were: locomotion, muscle relaxation, response to pain stimuli in the right thoracic and pelvic members and heart rate. These assessments were made at time 0 (immediately after injection) and times of 5, 10, 20, 30, 45, 60, 90, 120, 150 and 180 minutes after the injections.
\end{abstract}

RESULTS: Group 2 showed a higher heart rate than G1 and more rapid and prolonged immobilization.

CONCLUSION: The sedation scores obtained by these protocols (P1 and P2) were satisfactory, with possible pharmacological contention for collecting biological samples and physical examination in P. expansa.

Key words: Anesthesia. Midazolam. Ketamine. Turtles. Reptiles.

\section{RESUMO}

OBJETIVO: Avaliar os efeitos de duas associações anestésicas em tartarugas da Amazônia em (Podocnemis expansa).

MÉTODOS: Vinte P. expansa, hígidas, de ambos os sexos, com massa corporal entre 1,0 e 1,5 kg, de um criatório comercial localizado no vale do rio Araguaia, Goiás, Brasil, foram distribuídas em dois grupos ( $\mathrm{G} 1 \mathrm{n}=10$ e $\mathrm{G} 2 \mathrm{n}=10$ ). Cada grupo recebeu um protocolo sendo: P1 = midazolam $(2 \mathrm{mg} / \mathrm{kg}$ IM) com cetamina $(20 \mathrm{mg} / \mathrm{kg} \mathrm{IM})$ e $\mathrm{P} 2=$ midazolam $(2 \mathrm{mg} / \mathrm{kg} \mathrm{IM})$ com cetamina $(60 \mathrm{mg} / \mathrm{kg}$ IM), aplicados nos grupos G1 e G2, respectivamente. Os fármacos foram aplicados no membro torácico esquerdo. Os parâmetros clínicos avaliados foram: locomoção, relaxamento muscular, resposta aos estímulos dolorosos nos membros torácico direito e pelvinos e freqüência cardíaca. Essas avaliações foram feitas no tempo 0 (imediatamente após a injeção) e nos tempos 5, 10, 20, 30, 45, 60, 90, 120, 150 e 180 minutos após as injeções.

RESULTADOS: O G2 apresentou maior freqüência cardíaca que o G1 e imobilização mais rápida e prolongada.

CONCLUSÃO: As sedações obtidas por esses protocolos (P1 e P2) foram satisfatórias, sendo possível a contenção farmacológica para a coleta de amostras biológicas e exame físico em P. expansa.

Descritores: Anestesia. Midazolam. Ketamina. Tartarugas. Répteis. 


\section{Introduction}

Bennett $^{1}$ and Boyer ${ }^{2}$ when studying anesthesia in Testudines, noted that many drugs have been tested, but most showed limitations and side effects. According to Bennett ${ }^{1}$, anesthesia of reptiles is still an imprecise science, compared with birds and mammals, because the results tend to be highly variable, mainly because they are heterothermics. Additionally, this author states that anesthesia of reptiles is often complicated by the long induction and recovery periods and the difficulty of monitoring parameters.

Some works on anesthesia, in $P$ expansa species, have been performed by brazilian researchers. Santos et al. ${ }^{3}$ evaluated the effects of the combination of xylazine with propofol and Carvalho and Santos ${ }^{4}$ developed associations with tiletamine and zolazepam and ketamine with xylazine.

Dissociative anesthetics and benzodiazepines are some of the most used drugs for anesthesia and chemical restraint in reptiles ${ }^{5}$. The dissociative are used in high doses to achieve anesthesia and have long recovery periods. Already benzodiazepines are used mainly in association with the derivatives of phencyclidine $e^{5,6}$.

The midazolam is a water soluble drug, anxiolytic and anticonvulsant. Compared to diazepam it is 3-4 times more potent, and present faster metabolism. It has effects such as hypnosis, sedation, amnesia, muscle relaxation, low toxicity and does not alter heart rate, and cannot be used alone for anesthesia ${ }^{7}$.

The ketamine and the tiletamine, only representatives from the class of phencyclidine, are currently in clinical use. The widespread use of these agents in veterinary medicine is due to the fact that they have high safety margin when compared to barbiturates, because there is the possibility of administration by other routes, in addition to intravenous, and for being used in several home and wild animal species ${ }^{6}$.

According to Mello and Cordeiro ${ }^{8}$, ketamine increases heart rate, causes severe analgesia in the skeletal muscle system, but does not cause muscle relaxation nor loss of protective reflexes, keeping eyes open and pupils fixed.

The use of associations of ketamine with midazolam or ketamine with diazepam have been widespread, since they cause minimal side effects ${ }^{9}$ or no significant side effects on the cardiorespiratory system ${ }^{10}$. Bienzle and Boyd ${ }^{7}$ observed that the isolated use of midazolam and ketamine in snapping turtles (Chelydra serpentina), did not produce satisfactory sedation, but when combined, these drugs are very effective in reptiles.

The objective of this paper was to evaluate the effects of two anesthetic associations, midazolam $2 \mathrm{mg} / \mathrm{kg}$ IM with ketamine
$20 \mathrm{mg} / \mathrm{kg}$ IM and midazolam $2 \mathrm{mg} / \mathrm{kg}$ IM with ketamine $60 \mathrm{mg} /$ $\mathrm{kg}$ IM in $P$. expansa.

\section{Methods}

The experiment was conducted in a commercial breeding facility $\left(15^{\circ} 04^{\prime} 18^{\prime \prime} \mathrm{S}\right.$ and $50^{\circ} 25^{\prime} 2.4^{\prime \prime} \mathrm{W}-340 \mathrm{~m}$ altitude), located in the valley of the Araguaia River, Goias, Brazil. Ambient temperature was measured by maximum and minimum thermometer ${ }^{1}$.

Twenty specimens of $P$. expansa, healthy, aged approximately three years, of both sexes and body weight ranged from 1.0 to $1.5 \mathrm{~kg}$, were seized from their fattening tanks with the aid of nets, weighed and individually identified. Then, the terrapins were divided into two groups (G1 and G2), each group containing 10 subjects, fasted for 24 hours before being subjected to anesthetic protocols.

G1 received the anesthetic protocol P1 (midazolam 2 $\mathrm{mg} / \mathrm{kg}$ IM with ketamine $20 \mathrm{mg} / \mathrm{kg}$ IM) and G2, the anesthetic protocol P2 (midazolam $2 \mathrm{mg} / \mathrm{kg}$ IM with ketamine $60 \mathrm{mg} / \mathrm{kg} \mathrm{IM}$ ). Anesthetics midazolam ${ }^{2}$ and ketamine ${ }^{3}$ were mixed in the same syringe $(3 \mathrm{~mL})$ and injected intramuscularly into the left forelimb, using hypodermic needles $25 \times 0.70 \mathrm{~mm}$, after local antisepsis with $70 \%$ alcohol.

The anesthetic parameters were measured at $0,5,10,20$, $30,45,60,90,120,150$ and 180 minutes after the injections. Time zero was the moment of drug administration. Subjective scores of one (1) to minimal effect, two (2) for intermediate and three (3) to optimal effect were used to evaluate the following parameters:

- Locomotion: (1) animal with normal ability to move, (2) limited mobility and (3) absence of locomotion;

- Muscle relaxation: (1) the animal keeps the head elevated or retracted, (2) intermediate situation and (3) the head, limbs and tail remain relaxed.

For the test of pain sensitivity, the withdrawal response of the limb to clamping was considered score zero $(0)$ and its absence, score (1).

- Pain sensitivity in the right forelimb: with a curved hemostat Kelly $16 \mathrm{~cm}$ in the second latch on the phalanges of the hand, it is expected the response of the member's withdrawal to painful stimuli, classified as zero (0) and absence of response, one (1).

- $\quad$ Pain sensitivity of pelvic members: procedure similar to item 4 , but with clamping of the phalanges of the pelvic members;

Already to obtain the heart rate it was measured the 
quantity of heart beats per minute, using vascular Doppler ultrasound $^{4}$, at $0,10,30,60,120$ and 180 minutes after drug administration.

All procedures and assessments of the turtles were performed with average ambient temperature of $32.7^{\circ} \mathrm{C}( \pm 1.8)$.

The results were statistically analyzed by nonparametric Mann-Whitney U test, and the test was applied with a significance level of $5 \%$.

\section{Results}

G1 and G2 showed no significant difference for the parameters muscle relaxation and pain sensitivity in the thoracic and pelvic, in different times ( $\mathrm{p}>0.05$ ). However, for the parameters locomotion and heart rate, differences were observed $(\mathrm{p}<0.05)$ at times 5, 10, 90, 120, 150 and 180 and at 10, 30, 60, 120 and 180 minutes, respectively, as shown in Figures 1 and 2.

All P. expansa at G1 reached score two (2) twenty minutes after application for muscle relaxation, remaining only 40 minutes with this score, but for the test of pain sensitivity, the anesthetic protocol P1 was unable to neutralize the pain, having response to withdrawal of members of the right thoracic and pelvic limbs to painful stimuli.

In $\mathrm{G} 2$ only three individuals (30\%) reached score three (3) for muscle relaxation and a score (1) to pain sensitivity in the right thoracic and pelvic limbs. The other seven turtles of the group achieved only score two (2) for muscle relaxation and score zero (0) to test pain sensitivity of the limbs.

No studied reptile showed side effects from the drug administration.

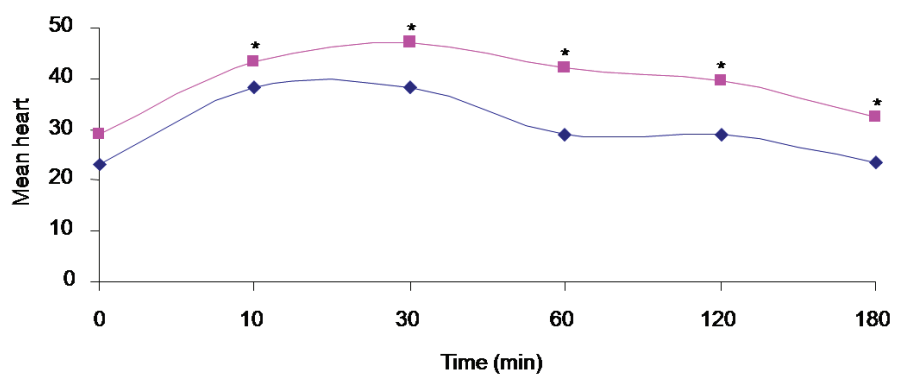

FIGURE 1 - Mean heart rates at different times in Podocnemis expansa (G1 and G2) subjected to different anesthetic protocols (P1 and P2). The asterisk indicates a difference between the groups $(\mathrm{p}<0.05)$.
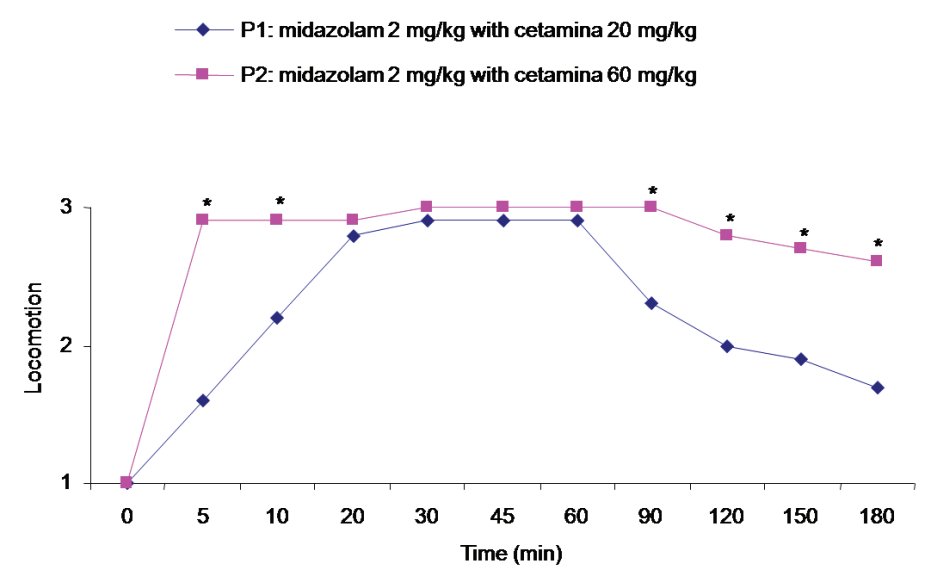

FIGURE 2 - Mean scores of locomotion observed at different times in Podocnemis expansa (G1 and G2) subjected to different anesthetic protocols ( $\mathrm{P} 1$ and $\mathrm{P} 2)$. The asterisk indicates that there were differences between groups $(\mathrm{p}<0.05)$.

\section{Discussion}

Ambient temperatures during the two protocols P1 and P2 were considered optimal because, as, according to Bennett ${ }^{1}$, the interval between 28 and $36^{\circ} \mathrm{C}$ causes the reptiles to have a better functioning of metabolism.

Hellyer et al. ${ }^{10}$ observed that the isolated administration of ketamine in greyhound dogs, produced excessive movements, violent induction and recovery, and seizures, but these effects were eliminated or minimized by joint administration of midazolam, for promoting muscle relaxation and hypnosis. Already Bienzle and Boyd $^{7}$ observed that in snapping turtles (Chelydra serpentina), the isolated use of ketamine ( $40 \mathrm{mg} / \mathrm{kg}$ IM) was not able to cause excitatory effects. In this study, there were no excitatory effect of ketamine on the Amazon river turtles (P. expansa) used in the experiment.

Even with the use of midazolam, there was no good muscle relaxation observed in both groups. G1 animals showed no loss of sensitivity in the thoracic and pelvic limbs and only three specimens of G2 presented it, thus showing that these protocols are not suitable for surgical procedures in $P$. expansa. However, Santos et al. ${ }^{11}$ when using midazolam as pre-anesthetical medication (2 mg/kg IM) in Phrynops geoffroanus observed good muscle relaxation, leading to easy handling and, therefore, ease of application of propofol in all Testudines. Oppenheim and Moon $^{12}$ also found good muscle relaxation inducing by applying midazolam doses of $1.5 \mathrm{mg} / \mathrm{kg}$ IM at $2.5 \mathrm{mg} / \mathrm{kg}$ IM in Trachemys scripta elegans.

The ketamine has the effect of cardiac stimulation, but its association with midazolam may reduce this effect ${ }^{9}$. In this study it 
was found that $\mathrm{G} 2$ showed heart rate means significantly higher ( $\mathrm{p}$ $<0.05)$ compared to $\mathrm{G} 1$ because of the higher amount of ketamine administered. Despite the use of midazolam, depending on the dose of ketamine used, it was not possible to control the heartbeat frequency of the turtles, suggesting that midazolam has limited capacity to manage these effects (Figure 1).

The specimens of G2 showed lower time for the start of immobilization, only five minutes, maintaining up to 180 minutes. Already G1 was restrained only for twenty minutes and the animals returned movement from 60 minutes (Figure 2). This fact corroborates the findings of Bienzle and $\mathrm{Boyd}^{7}$, whose anesthetic association of midazolam $2 \mathrm{mg} / \mathrm{kg}$ IM with ketamine $40 \mathrm{mg} / \mathrm{kg}$ IM and midazolam $2 \mathrm{mg} / \mathrm{kg}$ IM with ketamine $20 \mathrm{mg} / \mathrm{kg} \mathrm{IM}$, in snapping turtles (Chelydra serpetina) showed anesthetic effects at five minutes, sedation levels remained consistent between five and twenty minutes and turtles that received higher dose showed residual sedation. According to these authors, the association with higher dose of ketamine provided a consistent and more prolonged sedation. As Carvalho and Santos ${ }^{4}$, the higher the dose, the faster the induction and higher the duration of anesthetic effect.

According to Holz and $\mathrm{Holz}^{13}$, the combination of ketamine (60 mg/kg IM) and midazolam ( $2 \mathrm{mg} / \mathrm{kg}$ IM), in six redeared sliders (Trachemys scripta elegans), produced an adequate anesthetic level for surgery in all Testudines studied, however there was the death of one animal. Already Bienzle and Boyd ${ }^{7}$ stated that associations of ketamine (20 or $40 \mathrm{mg} / \mathrm{kg} \mathrm{IM}$ ) and midazolam ( $2 \mathrm{mg} / \mathrm{kg} \mathrm{IM}$ ), in snapping turtles (Chelydra serpentina), produced good sedation, and can thus be used only for chemical restraint of the species. In this study, while using the same association and the same doses, there was no animal death nor adequate anesthetic level for surgery observed for G2. However, Kruger and Pier ${ }^{14}$ conducted celiotomy in Testudo hermanni hermann, and Holz and Holz $^{15}$ cardiocentesis in Trachemis scripta elegans, both just using ketamine $60 \mathrm{mg} / \mathrm{kg}$ IM.

\section{Conclusions}

Both associations were effective for sedation, but are not suitable for surgical procedures in these animals.

The Testudines submitted to protocol P2 showed faster induction and more prolonged sedative effect.

\section{References}

1. Bennett RA. A review of anesthesia and chemical restraint in reptiles. J Zoo Wildl Med. 1991;22(3):282-303.

2. Boyer TH. Clinical anesthesia for Reptiles. Bull Assoc Rept Amphib
Vet. 1992;2(2):10-3.

3. Santos ALQ, Bosso ACS, Alves Junior JRF, Brito FMM, Pachaly JR, Avila Junior RH. Pharmacological restraint of captivity giant Amazonian turtle Podocnemis expansa (Testudines, Podocnemididae) with xylazine and propofol. Acta Cir Bras. 2008;23(3):270-3.

4. Carvalho SFM, Santos ALQ. Monitoramento cardíaco com ECG contínuo de Tartarugas da Amazônia (Podocnemis expansa, Schweigger, 1812) (Testudines) anestesiadas com associações de tiletamina e zolazepam ou cetamina e xilazina. Ars Vet. 2006;22(3):192-7.

5. Boyer TH. Emergency care of reptiles. Vet Clin North Am Exot Anim Pract. 1998;1(1):191-206.

6. Dupras J, Vachon P, Cuvelliez S, Blais D. Anestesia of the New Zeland rabbit using the combination of tiletamine-zolazepam and ketamine-midazolam with or without xilazine. Can Vet J. 2001;42(6):455-60.

7. Bienzle D, Boyd CJ. Sedative effects of ketamine and midazolam in snapping turtles (Chelydra serpentina). J Zoo Wildl Med. 1992;23(2):201-4.

8. Mello JRB, Cordeiro MRO. Avaliação da associação tiletaminazolazepam de três diferentes faixas etárias. Arq Fac Vet. 2001;29(1):14-24.

9. Jacobson JD, Hartsfield SM. Cardiovascular effects of intravenous bolus administration and infusion of ketamine-midazolam in dogs. Am J Vet Res. 1993;54(10):1710-4.

10. Hellyer PW, Freeman LC, Hubbell JA. Induction of anesthesia with diazepam-ketamine and midazolam-ketamine in greyhounds. Vet Surg. 1991;20(2):143-7.

11. Santos ALQ, Hirano LQL, Pereira PC, Silva JMM, Kaminishi APS, Bosso ACS. Anestesia de cágado-de-barbicha Phrynops geoffroanus Schweigger, 1812 (Testudines) com a associação midazolan e propofol. Acta Scientiarum. 2009;31(3):317-21.

12. Oppenhein YC, Moon PF. Sedative effects of midazolam in red eared slider turtles (Trachemis scripta elegans). J Zoo Wildl Med. 1995;26(3):409-13.

13. Holz P, Holz RM. Evaluation of ketamine, ketamine/xylazine, and ketamine/midazolam anesthesia in red-eared sliders (Trachemys scripta elegans). J Zoo Wild 1 Med. 1994;25(4):531-7.

14. Kruger J, Pier C. Futterverweigerung durch einen intestinalen Fremdkörper (Stein) bei einer griechischen Landschildkröte (Testudo hermanni hermanni). Die Kleintier-Praxis. 1994;39(5):343-51.

15. Holz RM, Holz P. Electrocardiography in anaesthetized red eared sliders (Trachemis scripta elegans). Res Vet Sci. 1995;58(1):67-9.

\section{Correspondence:}

André Luiz Quagliatto Santos

Universidade Federal de Uberlândia

Laboratório de Ensino e Pesquisa em Animais Silvestres

Avenida Pará, 1720, Campus Umuarama, Bloco T

38400-902 Uberlândia - MG Brasil

Tel.: (55 34)3218-2696

quagliatto@famev.ufu.br

Received: September 14, 2011

Review: November 16, 2011

Accepted: December 12, 2011

Conflict of interest: none

Financial source: none

${ }^{1}$ Research performed at Wild Animals Research Laboratory, Federal University of Uberlandia (UFU), Minas Gerais, Brazil. 